\title{
Two-year impact of praziquantel treatment for Schistosoma japonicum infection in China: re-infection, subclinical disease and fibrosis marker measurements
}

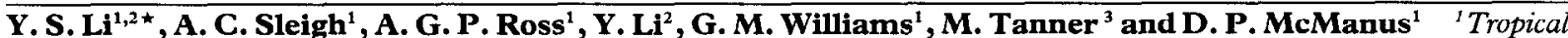 \\ Health Program, Australian Centre for International and Tropical Health and Nutrition, The Queensland Institute of Medical \\ Research and The University of Queensland, 300 Herston Road, Herston, Brisbane, Queensland 4029, Australia; ${ }^{2}$ Hunan \\ Institute of Parasitic Diseases, Huabanqiao Road, Yueyang, Hunan 414000, The People's Republic of China; ${ }^{3}$ Swiss Tropical \\ Institute, Socinstrasse 57, P. O. Box Ch-4002, Basel, Switzerland
}

\begin{abstract}
We studied a community cohort of 193 individuals exposed to endemic Schistosoma japonicum infection in the Dongting Lake region of China to assess subclinical morbidity and the 2-year benefit of curative therapy (praziquantel) administered in 1996. Prevalence and intensity of $S$. japonicum infection before treatment were $28 \%$ and 192 eggs per gram faeces (epg), respectively. Two years after cure, $22 \%$ of the cohort were reinfected, but with a lighter intensity (67 epg). Sixty-four subjects ( $37 \%)$ showed significant improvement in ultrasound parenchyma images after treatment and 51 subjects $(54 \%)$ showed significant improvement of periportal fibrosis. Left-lobe enlargement also reversed $(P<0.05)$ and splenomegaly reversed in 6 of 8 cases and developed in only 1 . Two years post-treatment a dilated portal vein became less frequent, but the decline was not significant $(16 \%$ vs $11 \%, P>0.05)$. The serum levels of laminin and collagen IV associated with reinfection and intensity and hyaluronic acid levels correlated with ultrasound findings $(P<0.01)$. Overall, treatment induced a marked decrease in subclinical hepatosplenic morbidity attributable to $S$. japonicum although low-intensity re-infection after treatment remained relatively frequent. Stratified analysis and logistic models evaluated potential confounding factors for assessment of treatment effects on hepatic fibrosis. S. japonicum infection and moderate-heavy alcohol intake interacted: improvement in parenchymal morbidity was impeded among drinkers $(P<0.05)$. Chemotherapy focused on at-risk residents controls prevalent subclinical hepatic fibrosis but re-infection indicates the need for complementary control strategies.
\end{abstract}

Keywords: Schistosoma japonicum, schistosomiasis, morbidity, re-infection, ultrasonography, fibrosis markers, China

\section{Introduction}

Schistosoma japonicum causes the most severe pathology of the 3 major schistosome species infecting humans (CHEN \& MOTT, 1988; JORDAN et al., 1993). The morbidity prevented by effective control has been studied clinically, but subclinical forms detectable by ultrasound are poorly understood and remain widespread in many endemic areas, even when infection prevalence is low (CAI et al., 1992; MOTT et al., 1992). Several million people are infected with $S$. japonicum in China and the Philippines, and millions more are at risk. The disease has an adverse impact on rural economies and has been the focus of Chinese health programmes for decades (LI et al., 1993; SLEIGH et al, 1998a). Control in some parts of China has made great progress, even before the advent of praziquantel, using integrated ecological approaches sustained over 40 years (SLEIGH et al., 1998b).

Schistosomiasis japonica remains a problem in marshland and mountain endemic areas of 6 Provinces in China (ANONymous, 1997, CHEN \& FENG, 1999). Reduction in morbidity is sought by use of periodic chemotherapy because many reports show its positive overall impact on schistosome prevalence, intensity and clinical disease (SLEIGH \& MOTT, 1986; SLEIGH et al., 1986; STURROCK et al., 1987; WIEST et al., 1992; BOOTH et al., 1996; OLDS et al., 1996; OLVEDA et al., 1996; LI, Y. S. et al., 1997). But the impact of community-based praziquantel on subclinical $S$. japonicum morbidity in China is not yet known (CAI et al., 1992; Ross et al., 1998a).

Hepatic fibrosis is the major morbid outcome of chronic infection with $S$. japonicum and many lesions are similar to those caused by $S$. mansoni. The liver pathology is caused by trapped eggs (SLEIGH \& MOTT, 1986; JORDAN et al., 1993) and is probably genetically associated (DESSEIN et al., 1999). Besides periportal fibrosis, there are changes in the liver parenchyma which are characteristic of $S$. japonicum infection. On ultrasound and computerized tomography these appear as images thought to result from progressive septal fibrosis

\footnotetext{
*Author for correspondence: phone +61733620401 , fax +617
} 33620104; e-mail yueshenL@qimr.edu.au and related clusters of calcified eggs (CHEUNG et al., 1996). However, little is known of the natural history of periportal or septal fibrosis due to this parasite, or the hepatic effects of treatment, re-infection, or concurrent damage due to alcohol or hepatitis $B$ virus infection.

Ultrasonography can stage hepatic fibrosis induced by Schistosoma infection. Decreases in the thickness of portal vein walls and in echogenic bands have been detected after praziquantel therapy (HOMEIDA et al., 1988; DOEHRING-SCHWERDTFEGER et al., 1989; OHMAE et al., 1992; WIEST et al., 1993; CAI et al., 1997; GERSPACHER-LARA et al., 1997; BOISIER et al., 1998) Assay of serum levels of fibrosis markers may be a useful supplementary tool for monitoring changes in liver fibrosis (SHAIIIN et al., 1992; KARDORrF et al., 1997; OBERTI et al., 1997; ESTERRE et al., 1998; RICARDBLUM et al., 1999).

We assessed the benefit of curing endemic $S$. japonicum infection by evaluating the effect on subclinical morbidity. The data were longitudinal and included repeated parasitological stool examinations, blinded sequential ultrasound findings and serum assay of 3 markers for fibrosis in a community cohort. We document residual subclinical morbidity and changes that occurred after chemotherapeutic cure and re-infection over 2 years. We relate subclinical changes to new and past infection, alcohol intake, hepatitis $\mathrm{B}$, and age.

\section{Materials and Methods \\ Study area}

The 5 study villages (population 2990) arc on 2 islands (Qingshan and Niangashan) in Dongting Lake, Hunan Province, China (LI, Y. S. et al., 1997; Ross et al., 1998a). Local residents, fishermen and buffaloes are the main infection source. Control programmes from 1988 to 1996 included periodic praziquantel treatment for those infected, health education and improved water supplies. Only $10 \%$ of the subjects in our cohort had never been treated before this study. Infection persists because of occupational exposure but clinically detectable liver and spleen enlargement has been controlled (BOOTH et al., 1996; Ross et al., 1998a). 


\section{Study design}

In 1996, we screened the resident population of the study area for active schistosome infection (1 stool, $3 \times 41.7-\mathrm{mg}$ Kato-Katz smears) and for continuing water exposure or past infection (questionnaire). All 250 individuals who were currently exposed and had past or present infection (Ross et al., 1998a; LI et al., 1999) received ultrasound assessment and then, whether found infected $(n=75)$ or not $(n=175)$ at baseline stool examination, received a single dose of praziquantel $(40 \mathrm{mg} / \mathrm{kg})$. Stool examination was repeated $7 \% 8$ weeks post-treatment and those still stool-positive $(n=13)$ were retreated, re-examined once more, and shown to be egg-negative. Thus all egg-positive subjects were cured in 1996 at the start of the study. In 1998, 2 years after treatment, $193(77 \%)$ of the 250 subjects initially selected had a final parasitological (2 stools, 6 KatoKatz smears per person) and ultrasound assessment. This group of 193 persons with ongoing exposure to re-infection constituted a 2-year prospective cohort enabling us to measure the influence of past, initial and re-infection with $S$. japonicum on the post-treatment evolution and regression of hepatic fibrosis.

The 193 cohort subjects were similar to the 250 eligible at baseline for mean age ( 39.7 vs $39 \cdot 2$ years), sex (males: $78 \%$ vs $76 \%$ ), and initial schistosome infection (prevalence: $30 \%$ vs $28 \%$; intensity: 204 vs $192 \mathrm{epg})$. Measurement bias for infection assessment was minimized by employing 2 experienced staff of the Hunan Institute of Parasitic Diseases to prepare and read all faecal smears. They were blinded to all other results. A $10 \%$ random sample of all smears was read by a third senior microscopist: concordance exceeded $95 \%$. To assess the influence of potential confounders of treatment effects, we recorded age, sex, reported alcohol intake and past history of anti-schistosomal chemotherapy. To explore the biological correlates of findings we tested $97 \%$ of the 193 cohort members for serum fibrosis markers. For 105 of the 193 (random selection from the serum panel) we measured 5 hepatitis B markers.

\section{Ultrasound measurements}

Ultrasound measurements were conducted by the same experienced observer before and 2 years after treatment. This person directed abdominal ultrasound services at a large hospital and was blinded to all other results and to the underlying study purpose. The equipment used was a portable ultrasonograph (Sonolayer$\mathrm{L}^{\mathrm{TM}}$ SAL-33B; Toshiba, Tokyo, Japan) with a $3 \cdot 5-\mathrm{MHz}$ sector probe. Standard positions, views, measurements and classifications were according to the CAIRO protocol (JENKINS \& HATZ, 1992; CAI et al. , 1997).

\section{Serum markers for fibrosis and hepatitis $B$}

Blood ( $5 \mathrm{~mL})$ was taken at a final assessment in 1998 All sera were separated within $12 \mathrm{~h}$, stored at $-20^{\circ} \mathrm{C}$, transported on dry ice to the Brisbane laboratory, and aliquoted and stored at $-70^{\circ} \mathrm{C}$ until used. Three serological fibrosis markers were measured using enzymelinked immunosorbent assays (EIA) for human laminin (LA) and collagen type IV (Fuji Chemical Industries, Tokyo, Japan) and human hyaluronic acid (HA) (Chugai Diagnostics Science, Tokyo, Japan). Values exceeding reference means by $>2 S D$ were considered abnormal; serum levels for LA, HA and collagen IV of $200 \mathrm{ng} / \mathrm{mL}$, $80 \mathrm{ng} / \mathrm{mL}$ and $150 \mathrm{ng} / \mathrm{mL}$, respectively, were the upper limits of normal when tested among healthy persons. For assessing hepatitis $\mathrm{B}$ virus (HBV) exposure, 5 markers ( $\mathrm{HBsAg}$, anti-HBs, $\mathrm{HBeAg}$, anti-HBe and anti-HBc) were tested by EIA using commercial kits (Nanyan Institute of Biochemical Reagents, Shenzhen, China). Subjects positive for 1 of the 5 markers were considered positive for HBV exposure (LI, Y. et al., 1997).

\section{Statistical analysis}

Infection intensity (eggs per gram faeces; epg) among infected sub-groups was expressed as the geometric mean ( \pm geometric SD); for whole populations (including uninfected persons) the (egg count +1 ) transformation was used for individual counts before calculating geometric means. Relative frequencies were compared by $\chi^{2}$ test for independent comparisons, or McNemar's test for paired analyses. Student's $t$-test (paired test when appropriate), or analysis of variance, was used to evaluate differences between or among group means. Non-parametric analysis of variance (Kruskal-Wallis) was used if Bartlett's test showed variances for compared groups were heterogeneous. Stratified analysis was used to assess potential confounding. For all outcomes assessed, the final logistic regression models included cure-ofheavy-infection (endpoint $<100 \mathrm{epg}$ ), moderate alcohol intake (weekly or more), older age ( $>35$ years) and past recurrent infection (treatment >twice) as explanatory variables. These variables provided the best fit for the outcomes studied. This produced adjusted odds ratio estimates for each variable allowing for the influence of all other variables in the model. For statistical inference $P$ values were set at $<0.05$, and relative risk $(R R)$ and odds ratio (OR) estimates were reported with $95 \%$ confidence intervals (CI). We distinguish between the magnitude of an effect (ranging from trivial to substantial) and its statistical significance (assessed by $P$-values) (ROTHMAN, 1986). Analysis used EpiInfo and SPSS software.

\section{Ethical consideration}

This study was approved by the local body for medical ethics in Hunan Province, China, and by the University of Queensland and the Queensland Institute of Medical Research. Individuals found to be re-infected with $S$. japonicum after 2 years received prompt oral treatment with praziquantel.

\section{Results}

\section{S. japonicum infection}

The initial prevalence of $S$. japonicum infection in the 193 pre-treatment cohort subjects and intensity among those positive were $28 \%(54 / 193)$ and $192 \pm 3.5 \mathrm{epg}$, respectively. Heavy-intensity $(\mathrm{epg} \geqslant 400)$ individuals comprised $6 \cdot 7 \%(n=13)$ of the cohort; males had higher prevalence $(29 \cdot 8 \%)$ and intensity among positives $(212 \pm 3.5 \mathrm{epg})$ than females $(21 \cdot 4 \% ; 116 \pm 3.1 \mathrm{epg})$. Children and adolescents (aged $<20$ years, $n=16$ ) had high prevalence and heavy intensity of infection $(62.5 \%$; $316 \mathrm{epg}$ ) and infection then declined slowly with age (Fig.). Two years after cure, $22 \cdot 3 \%(43 / 193)$ were found to be infected again with mean intensity among those positive ( $67 \pm 4.8 \mathrm{epg})$ one-third the corresponding level at baseline. Males had re-infection more commonly $(25.8 \%, 39 / 151)$ and higher intensity among those positive $(77 \pm 4.8 \mathrm{epg})$ than females $(9.5 \%, 4 / 42$ $18 \pm 2 \cdot 5 \mathrm{epg})$.

Children and adolescents had the highest re-infection $(37.5 \%)$ and incident intensity among those positive $(130 \pm 10 \mathrm{epg})$. Only $2 \cdot 6 \%(n=5)$ of the cohort had reinfection intensity $\geqslant 400 \mathrm{epg}$ at endpoint. The age pattern of re-infection after treatment was similar to that before (Fig.). Sixteen subjects $(29 \cdot 6 \%, 16 / 54)$ who were infected at baseline became re-infected and $27(19.4 \%$, 27/139) who had been negative at baseline had new incident infections. For the 16 individuals positive before and 2 years after treatment, mean intensity $(160 \pm$ $5.6 \mathrm{epg})$ at endpoint was much lighter $(P<0.005$, paired $t$-test) than at baseline $(389 \pm 3.9 \mathrm{epg})$.

\section{Hepatic parenchymal abnormalities}

Compared to $1996,36 \cdot 8 \%(64 / 174)$ of subjects improved parenchymal fibrosis in 1998 and $13.5 \%(23$ 171) became worse (Table 1). The prevalence of grade II-III in 1996 was $40.9 \%(n=79)$ but fell significantly to $28.5 \%(n=55)$ by $1998(P<0.01)$. The prevalence 


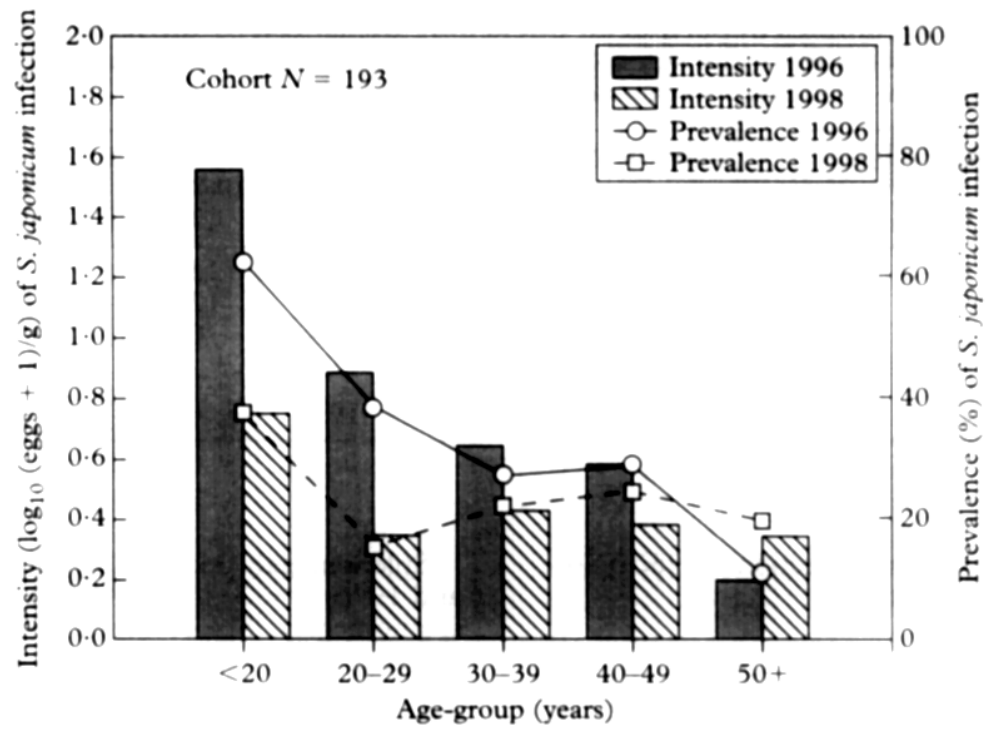

Figure. Cohort prevalence and intensity of infection with $S$. japonicum by age before (1996) and two years (1998) after praziquantel cure.

Table 1. Dynamics of parenchyma grading before and 2 years after treatment for control of schistosomiasis japonica in a cohort of 193 subjects (Dongting Lake region, 1996-98)

\begin{tabular}{lrrrrrrrr}
\hline $\begin{array}{l}\text { Parenchyma } \\
\text { grading }\end{array}$ & \multicolumn{9}{c}{ Parenchyma grading 1998 } & Progressed & $\begin{array}{c}\text { Reversed } \\
\text { 1996 }\end{array}$ & \multicolumn{1}{c}{0} & \multicolumn{1}{c}{ I } & II & III & Total & $(\%)$ & $(\%)$ \\
\hline 0 & 6 & 12 & 1 & 0 & 19 & $68 \cdot 4$ & - \\
I & 16 & 71 & 8 & 0 & 95 & $8 \cdot 4$ & $16 \cdot 8$ \\
II & 1 & 31 & $\mathbf{2 3}$ & 2 & 57 & $3 \cdot 5$ & $56 \cdot 1$ \\
III & 0 & 1 & 15 & 6 & 22 & - & $72 \cdot 7$ \\
Total $(N)$ & 23 & 115 & 47 & 8 & 193 & $(n=23)$ & $(n=64)$ \\
\hline
\end{tabular}

of grade II-III rose steadily as age increased (Table 2). Alcohol intake substantially and significantly impeded post-treatment improvement in grade II-III: $45 \cdot 6 \%$ of heavy drinkers ( $\geqslant$ weekly) improved in contrast to $70.8 \%$ of others $(P<0.05)$. Re-infection impeded improvement of grade II-III although this effect was less than for alcohol and was not significant: $51.2 \%(22 / 43)$ of reinfected improved and $64.7 \%(97 / 150)$ of others $(P>0.05)$.

For reversal of grade II-III, adjusted ORs showed a substantial but not statistically significant positive cureof-heavy-infection effect ( $\mathrm{OR}=2.55 ; 95 \% \mathrm{CI}=0.67-$ 9.58). Reversal effects were substantial and significantly negative for alcohol $(0.29 ; 0.08-0.91)$, older age $(0.15$; $0.03-0.74)$ and past recurrent infection $(0.32 ; 0 \cdot 10-$ 0.99 ). For incidence of grade II-III, the adjusted estimates were not statistically significant but the cure- of-infection effect appeared to be preventive $(0.50$; $0.05-4.99)$ and alcohol promotive (1.75;0.35-8.87); age and past recurrent infection had almost no effect.

\section{Periportal thickness}

Periportal thickening was found in $48.7 \%(n=94)$ in 1996 and $39.4 \%(n=76)$ in $1998(P<0.05)$ : over the 2 years $54.3 \%(51 / 94)$ improved and 10\% (19/190) got worse (Table 3 ). No one with grade II deteriorated, but 1 of 3 cases with grade III improved. Alcohol, re-infection, past infection, age and HBV had little influence on reversal of grade II-III. For incidence of grade II-III significant associations with explanatory variables were not found; however, OR point estimates for cure-ofheavy-infection (OR $=0.49 ; 95 \% \mathrm{CI}=0.04-4.98)$ suggested it may be preventive whereas older age $(1 \cdot 81$;

Table 2. Periportal and parenchyma (grading II-III) changes in 193 subjects by age at baseline and 2 years post treatment for control of schistosomiasis japonica

\begin{tabular}{|c|c|c|c|c|c|}
\hline \multirow{2}{*}{$\begin{array}{l}\text { Age } \\
\text { (years) }\end{array}$} & \multirow[b]{2}{*}{$n$} & \multicolumn{2}{|c|}{$\begin{array}{c}\text { Periportal } \\
(\% \text { of II-III) }\end{array}$} & \multicolumn{2}{|c|}{$\begin{array}{l}\text { Parenchyma } \\
\text { (\% of II-III) }\end{array}$} \\
\hline & & 1996 & 1998 & 1996 & 1998 \\
\hline $\begin{array}{l}<20 \\
20-35 \\
36-49 \\
50+\end{array}$ & $\begin{array}{l}16 \\
58 \\
65 \\
54\end{array}$ & $\begin{array}{r}6 \cdot 3 \\
6 \cdot 9 \\
24.6 \\
33.3\end{array}$ & $\begin{array}{c}0 \\
3 \cdot 4 \\
12 \cdot 3 \\
20 \cdot 4\end{array}$ & $\begin{array}{r}6 \cdot 3 \\
22 \cdot 4 \\
50 \cdot 8 \\
59 \cdot 3\end{array}$ & $\begin{array}{r}6 \cdot 3 \\
12 \cdot 1 \\
30 \cdot 8 \\
50 \cdot 0\end{array}$ \\
\hline
\end{tabular}


Table 3. Dynamics of periportal thickening measured by ultrasound in 193 cohort subjects from the schistosomiasis japonica-endemic Dongting Lake Region after treatment with praziquantel in 1996

\begin{tabular}{lrrrrrrrr}
\hline $\begin{array}{l}\text { Periportal } \\
\text { grading }\end{array}$ & \multicolumn{9}{c}{ Periportal grading 1998 } & Progressed & $\begin{array}{c}\text { Reversed } \\
(\%)\end{array}$ \\
\cline { 2 - 6 } 1996 & 0 & \multicolumn{1}{c}{ I } & II & III & Total & $(\%)$ & $(\%)$ \\
\hline 0 & $\mathbf{8 6}$ & 11 & 2 & 0 & 99 & $13 \cdot 1$ & - \\
I & 24 & $\mathbf{2 5}$ & 6 & 0 & 55 & $12 \cdot 7$ & $\mathbf{4 3 \cdot 6}$ \\
II & 7 & 19 & $\mathbf{1 0}$ & 0 & 36 & 0 & $72 \cdot 2$ \\
III & 0 & 0 & 1 & 2 & 3 & - & $1 / 3$ \\
Total $(N)$ & 117 & 55 & 19 & 2 & $\mathbf{1 9 3}$ & $(n=19)$ & $(n=51)$ \\
\hline
\end{tabular}

$0.33-9.83)$ and past recurrent infection $(7 \cdot 26 ; 0.80-$ $65 \cdot 41$ ) appeared to be promotive.

\section{Portal vein size}

A dilated portal vein (DPV) was demonstrated in $16.1 \%(n=31)$ and $11.4 \%(n=22)$ in 1996 and 1998 , respectively $(P>0.05)$. Subjects not re-infected had $8 \%(12 / 150)$ prevalence of DPV in 1998, substantially and significantly less than the prevalence of $23.3 \%$ (10/43) among those re-infected $(P<0 \cdot 01)$. Adjusted ORs for 2-year incidence of DPV showed a substantial and significant preventive effect for cure-of-heavy-infection ( $\mathrm{OR}=0.17 ; 95 \% \mathrm{CI}=0.03-0.83$ ), and moderate but not significant promotive effects for alcohol (1.43; $0.40-5 \cdot 13)$, age $(1.55 ; 0.43-5.62)$ and past recurrent infection $(1 \cdot 55 ; 0.43-5.52)$.

\section{Left-lobe and spleen enlargement}

Left-lobe enlargement (LLE) was seen in $26.4 \%$ $(n=51)$ in 1996 and $19.2 \%(n=37)$ in 1998 $(P<0.05)$. Although $15.5 \%(22 / 142)$ of individuals without LLE in 1996 developed it by $1998,68.6 \%(35 /$ 51) of baseline LLE reversed $(P<0.05)$. Incident LLE among the re-infected $(25 \%)$ was higher than for those not re-infected $(12.7 \%)(P>0.05)$. A substantial (but not significant) apparent preventive effect was noted for cure-of-heavy-infection (OR $=0.22 ; 95 \% \mathrm{CI}=0.06-$ $0 \cdot 83$ ).
Splenomegaly occurred in only $4 \cdot 1 \%(n=8)$ in 1996 and $1.6 \%(n=3)$ in 1998 . No one aged $<26$ years had splenomegaly. Six of the 81996 splenumegaly cases reverted after treatment. The 2 patients with persistent splenomegaly were aged $>61$ years. Only 1 person (aged 55 years) developed splenomegaly after treatment.

\section{Correlation of serum fibrosis markers with infection and morbidity}

Abnormal levels of LA, HA and collagen IV were found for $27.7 \%, 31.9 \%$ and $25.5 \%$ of the cohort, respectively. LA and collagen IV were higher in males; LA and collagen IV, but not HA, correlated with reinfection (Table 4). Subjects with moderate or heavy intensity infections $(>100 \mathrm{epg})$ had higher mean levels $(320 \pm 200 \mathrm{ng} / \mathrm{mL}$ ) of LA than those with light intensity $(211 \pm 71 \mathrm{ng} / \mathrm{mL})$ or no re-infection $(182 \pm 97 \mathrm{ng} / \mathrm{mL})$ $(P<0.01)$. Five cases with heavy intensity re-infection (epg >400) had even higher collagen levels $(307 \pm 387 \mathrm{ng} / \mathrm{mL})$, double the level for those not reinfected $(153 \pm 175 \mathrm{ng} / \mathrm{mL})(P<0.05)$. LA and collagen did not correlate with parenchymal and periportal findings $(P>0.05)$. HA correlated with parenchyma stages $(P<0.001)$ (Table 5$)$. Older subjects (aged $>50$ years) had higher HA levels $(157 \pm 163 \mathrm{ng} / \mathrm{mL})$ than those younger (aged $<50$ years; $58 \pm 75 \mathrm{ng} / \mathrm{mL}$; $P<0.01$ ).

Table 4. Serum levels of three fibrosis markers in 188 subjects with or without re-infection with $S$. japonicum

\begin{tabular}{lcccc}
\hline $\begin{array}{l}\text { Infection } \\
\text { status }\end{array}$ & $n$ & $\begin{array}{c}\text { Laminin } \\
(\mathrm{ng} / \mathrm{mL})\end{array}$ & $\begin{array}{c}\text { Collagen IV } \\
(\mathrm{ng} / \mathrm{mL})\end{array}$ & $\begin{array}{c}\text { Hyaluronic acid } \\
(\mathrm{ng} / \mathrm{mL})\end{array}$ \\
\hline Not re-infected & 145 & $182 \pm 97$ & $153 \pm 175$ & $83 \pm 109$ \\
Re-infected & 43 & $243 \pm 127$ & $197 \pm 226$ & $98 \pm 134$ \\
$P$ value $^{\mathrm{a}}$ & & $<0.001$ & $<0.05$ & $0>0.05$ \\
\hline
\end{tabular}

Values in the first 2 rows are mean $\pm \mathrm{SD}$.

${ }^{2}$ Kruskal-Wallis test.

Table 5. Serum levels of three fibrosis markers and endpoint ultrasound staging in 188 subjects in 1998 , two years after their treatment for schistosomiasis japonica

\begin{tabular}{|c|c|c|c|c|c|c|c|c|c|}
\hline \multirow[b]{2}{*}{$\begin{array}{l}\text { Fibrosis } \\
\text { markers }\end{array}$} & \multicolumn{4}{|c|}{ Parenchyma grading } & \multirow[b]{2}{*}{$P$ value $^{\mathrm{a}}$} & \multicolumn{3}{|c|}{ Periportal grading } & \multirow[b]{2}{*}{$P$ value $^{\mathrm{a}}$} \\
\hline & $\begin{array}{c}0 \\
(n=21)\end{array}$ & $\begin{array}{c}\mathrm{I} \\
(n=112)\end{array}$ & $\begin{array}{c}\mathrm{II} \\
(n=47)\end{array}$ & $\begin{array}{c}\text { III } \\
(n=8)\end{array}$ & & $\begin{array}{c}0 \\
(n=115)\end{array}$ & $\begin{array}{c}\mathrm{I} \\
(n=52)\end{array}$ & $\begin{array}{c}\mathrm{II}-\mathrm{III} \\
(n=21)\end{array}$ & \\
\hline $\begin{array}{l}\text { Laminin } \\
\text { Hyaluronic }\end{array}$ & $\begin{array}{r}185 \pm 101 \\
76 \pm 117\end{array}$ & $\begin{array}{r}193 \pm 94 \\
67 \pm 74\end{array}$ & $\begin{array}{l}203 \pm 142 \\
111 \pm 129\end{array}$ & $\begin{array}{l}219 \pm 85 \\
242 \pm 280\end{array}$ & $\begin{array}{l}0.6 \\
0.001\end{array}$ & $\begin{array}{r}190 \pm 112 \\
82 \pm 112\end{array}$ & $\begin{array}{c}209 \pm 106 \\
79 \perp 74\end{array}$ & $\begin{array}{l}195 \pm 77 \\
130 \pm 148\end{array}$ & $\begin{array}{l}0.45 \\
0.09\end{array}$ \\
\hline Collagen IV & $170 \pm 222$ & $151 \pm 182$ & $178 \pm 181$ & $217 \pm 222$ & 0.12 & $155 \pm 175$ & $178 \pm 221$ & $168 \pm 171$ & $0 \cdot 76$ \\
\hline
\end{tabular}

Values are mean $\pm \mathrm{SD}(\mathrm{ng} / \mathrm{mL})$.

${ }^{2}$ Kruskal-Wallis test. 


\section{Cumulative incidence and correlations for $\mathrm{HBV}$ infection}

Exposure to HBV affected 39\% of the cohort in 1998. Positive results for $\mathrm{HBsAg}$, anti-HBs, $\mathrm{HBeAg}$, anti- $\mathrm{HBe}$ and anti-HBc were found in $19 \%, 6.7 \%, 5.7 \%, 25 \cdot 7 \%$ and $18 \cdot 1 \%$, respectively. HBV prevalence did not vary much $(P>0.05)$ by age, sex, re-infection or ultrasonography findings. The serum levels of fibrosis markers in the 6 HBeAg-positive cases were higher (LA $435 \pm 300 \mathrm{ng} / \mathrm{mL} ; \mathrm{HA} 165 \pm 89 \mathrm{ng} / \mathrm{mL}$; collagen IV $438 \pm 459 \mathrm{ng} / \mathrm{mL})$ than those $(n=99)$ HBeAg-negative (LA $194 \pm 91 \mathrm{ng} / \mathrm{mL}$; HA $91 \pm 134 \mathrm{ng} / \mathrm{mL}$; collagen IV $153 \pm 167 \mathrm{ng} / \mathrm{mL}$ ). These differences were statistically significant (Kruskal-Wallis test, $P<0.05$ ) for LA and HA. When this comparison was restricted to those positive for $\mathrm{HBV}$, the $\mathrm{HBeAg}$-negative group still had lower levels of all 3 markers than those who were HBeAg-positive. However, the differences were significant for only LA and HA (Kruskal-Wallis test, $P<0.05$ )

\section{Discussion}

Praziquantel was first manufactured in China in 1984 and has been used for community treatment in the study locality since 1988 . Effectiveness of praziquantel is still unquestioned in this area and we observed an $83 \%$ cure (62/75) after a single dose. Most infected individuals in our study area now have low worm burdens (and infrequent splenomegaly) because chemotherapy has been used for more than a decade and other methods of control have been used since 1956 .

We measured the impact of curative treatment on $S$. japonicum infection and subclinical morbidity. After 2 years the infection incidence was high $(22 \%)$ but the prevalence and geometric mean intensity of infection fell, respectively, $21 \%$ and $65 \%$ below pre-treatment levels. Baseline subclinical hepatic morbidity was highly prevalent but fell by one-third or more over the 2 years after curative treatment. In this area a 2-year treatment cycle with coverage focused on those at risk will not control transmission but will control disease.

Parenchymal abnormalities were the most common and distinctive findings for all subclinical morbidity due to $S$. japonicum infection. This is notable given that these ultrasound features are found only with $S$. japonicum infection. Parenchymal pathology was slow to develop and was much less evident among the young, even when they were heavily infected. Despite the slow development, $30 \%$ of stage II-III cases improved quickly over the 2 years after treatment. But moderate alcohol intake, age $>35$ years and past recurrent infection impeded treatment-related reversal of parenchymal abnormalities substantially and significantly. In contrast, periportal fibrosis was less prevalent, slower to reverse and had no clear relationship to alcohol. Past recurrent infection was strongly related to periportal fibrosis, and prevention of heavy infection slowed its incidence substantially. Portal vein dilation fell substantially and significantly over the 2 years; its incidence was significantly related to re-infection. Several other findings, although not statistically significant, were noteworthy and consistent with our knowledge of the underlying biology. Thus left-lobe enlargement was associated with re-infection, and its reversal with cure of heavy infection. Spleen enlargement reduced substantially and persisted or developed only in 3 subjects, all aged $>50$ years.

With $S$. japonicum, few reports have explored the dynamic relationship over time between infection and hepatic fibrosis measured by ultrasound using the CAIRO standard. Previous studies have correlated periportal fibrusis measured by ultrasound with biopsyproven liver pathology in individuals infected by $S$. mansoni (HOMEIDA et al., 1988; DOEHRINGSCHWERDTFEGER et al., 1989). In this study we could not perform liver biopsies. The area is remote and lacks hospital facilities or adequate transport. In such a setting, risks of liver biopsy outweigh personal benefit and performance of the procedure would be unethical.

Liver fibrosis is a complex process involving production and deposition of insoluble components that constitute the extracellular matrix. The major components of basement membranes are type IV collagen, LA and heparin sulphate proteoglycan. HA is a glycosaminoglycan and is mainly synthesized by hepatic stellate cells and taken up and degraded almost exclusively in hepatic sinusoidal endothelial cells. In this study we found serum concentrations of LA and collagen IV correlated well with active schistosome infection, manifest by egg excretion. This suggests that LA and collagen IV may be involved in inflammatory granulomas and pseudotubercle formation around trapped eggs. Serum concentration of HA, but not of LA and collagen IV, correlated well with ultrasound grading of fibrosis. Thus it appears that LA and collagen IV levels respond to egg-associated inflammation and $\mathrm{HA}$ to fibrosis. Serum markers for individuals were rather insensitive and non-specific predictors of fibrosis but mean levels of these markers in populations may indicate endemic infection and fibrosis that would fall with effective control.

Prevalence of $\mathrm{HBV}$ exposure was similar for patients with and without hepatic fibrosis detected by ultrasound. HBV was studied in only $54 \%$ of the cohort and our data lacked statistical power for investigating this factor as a codeterminant of fibrosis. But the stable HBV exposure rate (40\% in 1992 (LI, Y. et al., 1997) and 39\% in 1998) suggests that improvement in hepatosplenic morbidity in the 2 years that followed praziquantel treatment in 1996 cannot be attributed to changes in $\mathrm{HBV}$ in this population.

Age or body height may influence the normal size of organs measured by ultrasound (YAZDANPANAH et al., 1997). We did not adjust for body weight and height because our study involved self-comparison of ultrasonography before and after treatment. Also, we did not use the CAIRO integrated grading system for hepatic fibrosis as we aimed to assess the dynamics separately for both parenchyma and periportal changes. Alcohol exposure was investigated by questionnaire and we accept that consumption of alcohol based on self-report is difficult to validate. Despite the measurement difficulties, trends linking alcohol to parenchymal features of $S$. japonicum infection were easily detected, and have not been reported before.

Our 2-year study quantified the substantial morbidity bcnefit of lowering S. japonicum worm burdens by at least half for 2 years. Although re-infection 2 years after therapy remained relatively frequent, both the intensity of infection and the morbidity attributable to this parasite were markedly reduced. But chemotherapy-based control in China faces several problems, including low compliance from local populations (WIEST et al., 1991; LI, Y.S. et al., 1997; Ross et al., 1998b) partly caused by concurrent over-prescribing of supplementary medicines as an income-earning device for village doctors. As well, because successive stool egg counts vary and symptoms may be minimal, lightly infected persons may remain undetected and miss periodic community-based treatments.

In future, control based on chemotherapy in China could focus on those shown by questionnaire or past history to be at high risk of infection. Also, our data show that moderate - heavy alcohol intake exacerbates schistosome-induced parenchymal morbidity, and this message should be incorporated into health education and healthy lifestyle programmes of the future. In addition, ecological interventions to reduce human or bovine exposure or faecal contamination of transmission sites, or vaccines that prevent infection or lower egg production would complement the power of praziquantel.

\section{Acknowledgements}

The authors gratefully thank Dr Xiaolin $\mathrm{He}$ from the Ultrasound Department of Yueyang Anti-Schistosomiasis Hospital 
who gave generously of her time and energy in ultrasound examinations. We also sincerely thank the patients who took part in this study and the support staff from Hunan Institute of Parasitic Diseases, without whose total cooperation this project would not have been possible. We thank the AMRAD Corporation Ltd, Australia, and Chugai Diagnostic Science Corporation, Japan for provision of the anti-human hyaluronic acid test kits in this study. This study was supported by the National Health and Medical Research Council of Australia, the Swiss Tropical Institute and the United Development Programme/ World Bank/World Health Organization Special Programme for Research and Training in Tropical Diseases.

\section{References}

Anonymous (1997). Epidemic status of schistosomiasis in China: a national-wide sampling survey in 1995. Beijing: Chinese Journal of Schistosomiasis Control Press.

Boisier, P., Ramarokoto, C.-E., Ravaoalimalala, V. E., Rabarijaona, L., Serieye, J., Roux, J. \& Esterre, P. (1998). Reversibility of Schistosoma mansoni-associated morbidity after yearly mass praziquantel therapy: ultrasonographic assessment. Transactions of the Royal Society of Tropical Medicine and Hygiene, 92, 451-453.

Booth, M., Li, Y. S. \& Tanner, M. (1996). Helminth infections, morbidity indicators and schistosomiasis treatment history in three villages, Dongting Lake region, PR China. Tropical Medicine and Intemational Health, 1, 464-474.

Cai, W. M., Qiu, D. C. \& Hatz, C. (1992). Studies on ultrasonographic diagnosis of schistosomiasis japonica in China - a review of selected Chinese studies. Acta Tropica, $51,37-43$.

Cai, M., Chen, Z., Chen, F., Zhou, C., Liu, R. \& Wang, J. X. (1997). Changes of ultrasonography and two serum biochemical indices for hepatic fibrosis in schistosomiasis japonica patients one year after praziquantel treatment. Chinese Medical fournal, 110, 797-800.

Chen, M. G. \& Feng, Z. (1999). Schistosomiasis control in China. Parasitology International, 48, 11-19.

Chen, M. G. \& Mott, K.E. (1988). Progress in the assessment of morbidity due to Schistosoma japonicum infection: a review of recent literature. Tropical Diseases Bulletin, 85, 1-44.

Cheung, H., Lai, Y. M., Loke, L. L., Lee, K. C., Ho, W. C., Choi, C. H.\& Metreweli, C. (1996). The imaging diagnosis of hepatic schistosomiasis japonica sequelae. Clinical Radiology, 51, 51-55.

Dessein, A. J., Hillaire, D., Elwali, N. E., Marquet, S., Mohamed-Ali, Q., Mirghani, A., Henri, S., Abdelhameed, A. A. Saeed, O. K. Magzoub, M. M. \& Abel, L. (1999). Severe hepatic fibrosis in Schistosoma mansoni infection is controlled by a major locus that is closely linked to the interferon-gamma receptor gene. American foumal of Human Genetics, 65, 709-721

Doehring-Schwerdtfeger, E., Abdel-Rahim, I. M., MohamedAli, Q., Kardorff, R., Franke, D., Kaiser, C., Elsheikh, M. \& Ehnrich, J. H. (1989). Sonomorphological abnormalities in Sudanese children with Schistosoma mansoni infection: a proposed staging system for field diagnosis of peripurtal fibrosis. American foumal of Tropical Medicine and Hygiene, 41, 63-69.

Esterre, P., Raobelison, A., Ramarokoto, C. E., Ravaoalimalala, V. E., Boisier, P. \& Roux, J. (1998). Serum concentrations of sICAM-1, sE-, sP- and sL-selectins in patients with Schistosoma mansoni infection and association with disease severity. Parasite Immunology, 20, 369-376.

Gerspacher-Lara, R., Pinto-Silva, R. A., Rayes, A. A. M., Drummond, S. C. \& Lambertucci, J. R. (1997). Ultrasonography of periportal fibrosis in schistosomiasis mansoni in Brazil. Transactions of the Royal Society of Tropical Medicine and Hygiene, 91, 307-309.

Homeida, M., Abdel Gadir, A. F., Cheever, A. W., Bennett, J. L., Arbab, B. M., Ibrahium, S. Z., Abdel Salam, I. M. Dafalla, A.A. \& Nash, T.E. (1988). Diagnosis of pathological confirmed Symmers' periportal fibrosis by ultrasonography; a prospective blinded study. American foumal of Tropical Medicine and Hygiene, 38, 86-91.

Jenkins, J. M. \& Hatz, C. (1992). The use of diagnostic ultrasound in schistosomiasis: attempts at standardization of methodology. Acta Tropica, 51, 45-63.

Jordan, P., Webbe, G. \& Sturrock, R. F. (1993). Human Schistosomiasis, 3rd edition. Wallingford: $\mathrm{CAB}$ International.

Kardorff, R., Gabone, R. M., Mugashe, C., Obiga, D., Ramarokoto, C. E., Mahlert, C., Spannbrucker, N., Lang, A., Günzler, V., Gryseels, B., Ehrich, J. H. H. \& Doehring, E. (1997) Schistosoma mansoni-related morbidity on Ukerewe Island, Tanzania: clinical, ultrasonographical and biochem- ical parameters. Tropical Medicine and International Health, $\mathbf{2}$, 230-239.

Li, Y., Yu, D. B., Li, Y. S., Ross, A. G. P. \& McManus, D. P. (1997). Infections with hepatitis B virus in three villages endemic for schistosomiasis japonica in the Dongting Lake region of China. Annals of Tropical Medicine and Parasitology, 91, 323-327.

Li, Y. S., Li, Y., Yu, D. B., Hu, S. Q., Xiang, Y. \& Zhong, Z. N. (1993). A multivariate analysis of the relationship between the workability and $S$. japonicum infection in China. Revista do Instituto de Medicina Tropical de São Paulo, 35, 347-353.

Li, Y. S., Ross, A. G. P., Yu, D. B., Li, Y., Williams, G. M. \& McManus, D. P. (1997). An evaluation of Schistosoma japonicum infections in three villages in the Dongting lake region of China. I. Prevalence, intensity and morbidity before the implementation of adequate control strategies. Acta Tropica, 68, 77-91.

Li, Y. S., Sleigh, A. C., Ross, A. G. P., Li, Y., Williams, G. M., Forsyth, S. J., Tanner, M. \& McManus, D. P. (1999). A 2year prospective study in China provides epidemiological evidence for resistance in humans to re-infection with $S$ chistosoma japonicum. Annals of Tropical Medicine and Parasitology, 93, 629-642.

Mott, K. E., Chen, M. G., Abdel-Wahab, F., Burki, A., Dixon, H., Xu, F. N. \& Yu, S. H. (1992). Liver ultrasound findings in a low prevalence area of $S$. japonicum in China: comparison with history, physical examination, parasitological and serological results. Acta Tropica, 51, 65-84.

Oberti, F., Valsesia, E., Pilette, C., Rousselet, M. C., Bedossa, P., Aube, C., Gallois, Y., Rifflet, H., Maiga, M. Y., Fontbonne, D. \& Cales, P. (1997). Noninvasive diagnosis of hepatic fibrosis or cirrhosis. Gastroenterology, 113, 16091616.

Ohmae, H., Tanaka, M., Hayashi, M., Matsuzaki, Y., Kurosaki, Y., Blas, B. L., Portillo, G. G., Sy, O. S. \& Yasuraoka, K. (1992). Improvement of ultrasonographic and serologic changes in Schistosoma japonicum infected patients after treatment with praziquantel. American foumal of Tropical Medicine and Hygiene, 46, 99-104.

Olds, G. R., Olveda, R., Wu, G., Wiest, P., McGarvey, S., Aligui, G., Zhang, S., Ramirez, B., Daniel, B., Peters, P., Romulo, R., Fevidal, P., Tiu, W., Yuan, J., Domingo, E. \& Blas, B. (1996). Immunity and morbidity in schistosomiasis japonica infection. American foumal of Tropical Medicine and Hygiene, 55(supplement), 121-126.

Olveda, R. M., Daniel, B. L., Ramirez, B. D. L., Aligui, G. D. L., Acosta, L. P., Fevidal, P., Tiu, E., de Veyra, F., Peters, P. A., Romulo, R., Domingo, E., Wiest, P. M \& Olds, G. R. (1996). Schistosomiasis japonica in the Philippines: the long-term impact of population-based chemotherapy on infection, transmission, and morbidity. Foumal of Infectious Diseases, 174, 163-172.

Ricard-Blum, S., Hartmann, D. J., Grenard, P., Ravaoalimalala, V. E., Boisier, P. \& Esterre, P. (1999). Relationships between several markers of extracellular matrix turn-over and ultrasonography in human schistosomiasis mansoni. American fournal of Tropical Medicine and Hygiene, 60, 658-663.

Ross, A. P. G., Li, Y. S., Booth, M., Sleigh, A. C., Williams, G. M. \& McManus, D. P. (1998a). Five year impact of chemotherapy on morbidity attributable to Schistosoma japonicum infection in the Dongting Lake region. Tropical Medicine and International Health, 3, 837-841.

Ross, A. P. G., Sleigh, A. C., Li, Y. S., Williams, G. M., Li, Y., Waine, G. J., Tang, G. T., Forsyth, S. J. \& McManus, D. P. (1998b). Epidemiological identification of Chinese individuals putatively susceptible or insusceptible to Schistosoma japonicum: a prclude to immunogenetic study of human resistance to Asian schistosomiasis. Annals of Tropical Medicine and Parasitology, 92, 765-774.

Rothman, K. J. (1986). Modern Epideminlogy. Boston: Little, Brown and Company.

Shahin, M., Schuppan, D., Waldherr, R., Risteli, J., Risteli, L., Savolainen, E. R., Oesterling, C., Rahman, H. M. A., Sahly, A. M. E., Razek, S. M. A., Ruby, O. E. \& Seitz, H. K. (1992) Serum procollagen peptides and collagen type VI for the assessment of activity and degree of hepatic fibrosis in schistosomiasis and alcoholic liver disease. Hepatology, 15, 637-644.

Sleigh, A. C. \& Mott, K. E. (1986). Schistosomiasis. Clinics in Tropical Medicine and Communicable Diseases, 1, 643-668.

Sleigh, A. C., Hoff, R., Mott, K. E., Maguire, J. H. \& da Franca Silva, J.T. (1986). Manson's schistosomiasis in Brazil: 11ycar cvaluation of successful disease control with oxamniquine. Lancet, $\mathbf{i}, 635-637$

Sleigh, A., Li, X., Jackson, S. \& Huang, K. (1998a). Eradication 
of schistosomiasis in Guangxi, China. Part 1. Setting, strategies, operations, and outcomes, 1953-92. Bulletin of the World Health Organization, 76, 361-372.

Sleigh, A., Li, X., Jackson, S. \& Huang, K. (1998b). Eradication of schistosomiasis in Guangxi, China. Part 3. Community diagnosis of the worst-affected areas and maintenance strategies for the future. Bulletin of the World Health Organization, 76, 581-590.

Sturrock, R. F., Bensted-Smith, R., Butterworth, A. E., Dalton, P. R., Kariuki, H. C., Koech, D., Mugambi, M., Ouma, J. H. \& Arap Siongok, T. K. (1987). Immunity after treatment of human schistosomiasis mansoni. III. Long-term effects of treatment and re-treatment. Transactions of the Royal Society of Tropical Medicine and Hygiene, 81, 303-314.

Wiest, P. M., Wu, G., Zhong, S., McGarvey, S. T., Yuan, J., Olveda, R. M., Peters, P. A. \& Olds, G. R. (1991). Impact of annual screening and chemotherapy with praziquantel on schistosomiasis japonica on Jishan Island, People's Republic of China. American fournal of Tropical Medicine and Hygiene, 51, 162-169.

Wiest, P. M., Wu, G., Zhang, S., Yuan, J., Peters, P. A. S. McGarvey, S. T., Tso, M., Olveda, R. \& Olds, G. R. (1992)
Morbidity due to schistosomiasis japonica in the People's Republic of China. Transactions of the Royal Society of Tropical Medicine and Hygiene, 86, 47-50.

Wiest, P. M., Wu, G., Zhong, S., McGarvey, S. T., Tan, E., Yuan, J., Peters. P., Olveda, R. M. \& Olds, G. R. (1993). Schistosomiasis japonica on Jishan Island, Jiangxi Province, People's Republic of China: persistence of hepatic fibrosis after reduction of the prevalence of infection with age. Transactions of the Royal Society of Tropical Medicine and Hygiene, 87, 290-294.

Yazdanpanah, Y., Thomas, A. K., Kardorff, R., Talla, I., Sow, S., Niang, M., Stelma, F. E., Decam, C., Rogerie, F., Gryseels, B., Capron, A. \& Doehring, E. (1997). Organometric investigations of the spleen and liver by ultrasound in Schistosoma mansoni endemic and nonendemic villages in Senegal. American fournal of Tropical Medicine and Hygiene, $57,245-249$

Received 9 fuly 1999; revised 28 September 1999; accepted for publication 6 October 1999

\section{Announcements}

\section{Working in the tropics-how to do it
A joint meeting of the Royal Society of Tropical Medicine and Hygiene, the Wellcome Trust and the Medical Research Council}

Manson House, London, UK

9 May 2000

Interested in research? Want to work in the tropics?

Ever wondered how to go about it as a basic scientist or a doctor?

This is the meeting for you!

The objective of this meeting is to encourage and assist doctors and scientists with an interest in carrying out research in the tropics. Speakers include directors from Wellcome Trust and MRC Tropical Centres (including: Prof. Kevin Marsh, KEMRI-Wellcome Trust, Kenya; Dr Steve Allen, Director of Training, MRC Laboratories, The Gambia; Prof. Eleanor Riley, London School of Hygiene and Tropical Medicine, UK). Also hear from trainees who have done it and survived. Representatives of the Wellcome Trust, MRC, Department for International Development and the International Health Exchange will talk about funding opportunities. All speakers will be available for informal discussion.

Admission free, but all participants must register beforehand. Closing date for applications, Tuesday 2 May 2000. Application forms available from the Royal Society of Tropical Medicine and Hygiene, Manson House, 26 Portland Place, London W1N 4EY, UK; phone +44 (0)20 7580 2127, fax +44 (0)207436 1389, e-mail mail@rstmh.org

\section{American Society of Tropical Medicine and Hygiene 49th Annual Meeting}

Houston, TX, USA

29 October-2 November 2000

For more information, please contact ASTMH Headquarters, 60 Revere Drive, Suite 500, Northbrook, IL 60062, USA; phone +1 847480 9592, fax +1 847480 9282, e-mail astmh@astmh.org, web site www.astmh.org 